\title{
Correspondence
}

\section{Beyond dualism and defamation: utility and action}

A more interesting question than 'where does the truth lie?' is to ask what are the implications for persons and society of the respective positions of Szasz ${ }^{1}$ and Shorter. ${ }^{2}$ Even respected nosologists, explicitly acknowledged in the American Psychiatric Association's Research Agenda for DSM-5, have abandoned the quest of establishing nosological validity (on the basis of the failure of even modified Feighner criteria) for most psychiatric 'disorders', but instead are asking questions about the utility of different diagnostic criteria. ${ }^{3}$ Therefore, if Szasz is right and mental illness is a metaphor, the Shorter camp might productively ask 'is it a useful metaphor?' instead of reverting to a wholly outdated mind-body dualism.

Functional brain imaging reflects lived mental states, and particular brain areas may 'light up' in response to a person's interaction with others and their environment, without necessarily implying neurological causality. Even structural brain changes can in fact imply interpersonal and environmental causality, as the neuroimaging exploring the impact of childhood maltreatment makes clear. ${ }^{4}$ And 'difference' of course does not automatically imply 'disease', as the neurodiversity movement has so eloquently argued. ${ }^{5}$

Individual mental phenomena can be simultaneously described at multiple theoretical levels - from neural networks and psychological descriptions through to narrative, meaning and conscious experience - with bidirectional influence between levels. How neuropsychological processes are recursively embedded within wider social processes is more complex still, although social looping theory is a useful starting point here. ${ }^{6}$ The ability, however, to hold multiple levels of description in mind often breaks down when meaning is translated into action. The belief that the 'voices in my head' are due to a progressive neurological disease as opposed to a disgruntled ancestor or spirit has almost irreconcilable consequences for action. The first signifies a need for medical treatment, presumably medication, the second perhaps a need for dialogue or appeasement with the ancestor/spirit (or, within our contemporary psychologised cultural milieu, perhaps dialogue and integration with this voice/'split-off self part'). Members of the Hearing Voices Network would hold to whatever appears useful. ${ }^{7}$ New meanings may themselves influence psychological and associated neurological processes reinforced by social looping. ${ }^{6}$ Medication can only be reconciled with the ancestor/spirit metaphor as 'something that might take the edge of my distress' while engaging with this process of restitution, although not all voice-hearers find this acceptable or necessary.

Szasz questioned the implications for individual agency and personal responsibility of attributing difficult or criminal behaviour to illness. Even if we are not prepared to accept this position indiscriminately, for those already given a diagnosis we can be challenged to ask where the boundary lies between illness and illness behaviour.

There is therefore a real scientific debate to be had. The Research Agenda for DSM-5 proposes empirically testing the utility of different diagnostic criteria for the 'mental disorders' ${ }^{3}$
This evaluation process could be expanded beyond diagnosis to testing out the utility of wider non-diagnostic formulations (where used as an alternative rather than an addition to diagnosis) and linked interventions, on short- and longer-term outcomes (provided that outcome measures reflect what is meaningful to patients/clients, rather than being merely symptom based). Increasing numbers of practitioners are now challenging the value of diagnosis-based systems (see www.causes.com/causes/615071-no-more-psychiatric-labels/ about). Evaluating such different modes of practice lends itself to real science, rather than to the moral defamation resorted to by Shorter in his assertion that critically minded practitioners are responsible for, and indifferent about, countless suicides. Where is the evidence that the massive worldwide increase in antidepressant prescribing has had a significant impact on suicide reduction?

1 Szasz T. The myth of mental illness: 50 years later. Psychiatrist 2011; 35: 179-82.

2 Shorter E. Still tilting at windmills. Commentary on ... The myth of mental illness. Psychiatrist 2011; 35: 183-4.

3 Kupfer DJ, First MB, Regier DA (eds). A Research Agenda for DSM-V. American Psychiatric Association, 2002.

4 Teicher MH, Andersen SL, Polcari A, Anderson CM, Navalta CP, Kim DM. The neurobiological consequences of early stress and childhood maltreatment. Neurosci Biobehav Rev 2003; 27: 33-44.

5 Fenton A, Krahn T. Autism, neurodiversity and equality beyond the 'normal'. J Ethics Ment Health 2009; 2: 2.

6 Seligman R, Kirmayer LJ. Dissociative experience and cultural neuroscience: narrative, metaphor and mechanism. Cult Med Psychiatry 2008; 32: 31-64.

7 Romme M, Escher S. Accepting Voices. Mind Publications, 1993.

James Rodger, Specialty Registrar (ST6), Sussex Partnership NHS Foundation Trust, UK, email: j.rodger@nhs.net

doi: 10.1192/pb.35.11.430

\section{Removal of experts immunity}

The papers by Thompson ${ }^{1}$ and $\mathrm{Rix}^{2}$ provide useful information for anyone thinking of entering the field of medico-legal work. Anyone in this position will also want to be aware that earlier on this year, in Jones v. Kaney, ${ }^{3}$ the Supreme Court decided by a majority of 5 to 2 to remove the immunity that expert witnesses have previously enjoyed. It is too early to say how this is going to affect such work.

I have provided independent reports for solicitors for some years and I think that I have learnt as much from this clinically as anything else I have done. Now more than ever, though, I think it is essential that anyone carrying out such work obtains proper training, carries adequate insurance and pays attention to specific CPD for this, including joining a CPD peer group that can monitor this work and provide helpful support.

Medico-legal work is interesting and challenging, but it does require sound foundations. 